\title{
SIMULAÇÃO DAS EMISSÕES ATMOSFÉRICAS DO PROCESSO KRAFT DE PRODUÇÃO DE CELULOSE NA QUALIDADE DO AR
}

\author{
J. R. MELO ${ }^{1 *}$, E. P. LIMA² e M. L. GIMENES ${ }^{1}$ \\ ${ }^{1}$ Universidade Estadual de Maringá (UEM), *bolsista CAPES, Departamento de Engenharia Química \\ ${ }^{2}$ Universidade Estadual de Maringá (UEM), Departamento de Tecnologia \\ E-mail para contato: rmjoelma@gmail.com
}

\begin{abstract}
RESUMO - A produção de celulose Kraft está associada à emissão dos poluentes material particulado (MP), compostos reduzidos de enxofre (TRS) e óxidos de enxofre $\left(\mathrm{SO}_{\mathrm{x}}\right)$ que podem causar danos ao ambiente, ao patrimônio e a saúde do humana. O objetivo do trabalho foi o de avaliar a qualidade do ar sobre uma cidade na região centro-leste do Paraná, utilizando o modelo de dispersão atmosférica Aermod para estimar a concentração dos poluentes: MP, TRS e $\mathrm{SO}_{\mathrm{x}}$. A construção do cenário da simulação consiste em caracterizar: a área de estudo; as fontes emissoras; a topografia da região; e os dados meteorológicos. Os resultados das simulações mostram que o centro da cidade foi atingido pela pluma de poluentes, porém não foi o mais impactado. As áreas mais impactadas estão a noroeste e sudeste das fontes, para a maioria dos casos. As concentrações máximas estimadas pelo modelo com médias horária, diária e anual mantiveram-se inferiores às concentrações estabelecidas pela Resolução Conama $\mathrm{n}^{\circ} 003 / 1990$ e padrões da USEPA, para o poluente TRS. Conclui-se que o modelo pode ser utilizado de maneira qualitativa, indicando os possíveis pontos de medidas da concentração de poluentes em uma rede de monitoramento da qualidade do ar.
\end{abstract}

\section{INTRODUÇÃO}

A qualidade do ar é diretamente influenciada pela distribuição e intensidade da emissão de poluentes atmosféricos (CETESB, 2012). Os níveis de poluição são definidos a partir da quantificação das substâncias poluentes presentes no ar. No entanto, a maioria das cidades brasileiras não apresenta redes de monitoramento da qualidade do ar e, quando existem redes de monitoramento, estas se apresentam localizadas somente em algumas capitais do Estado (IAP, 2013). Na ausência de monitoramento e indisponibilidade de dados de medidas de poluentes, de acordo com a legislação brasileira, relatada no artigo 75 da Resolução Sema n54/2006, é possível estimar a concentração de poluentes por modelos matemáticos, que simulam o transporte de poluentes na atmosfera (BRASIL, 2006a).

Desta forma, o presente trabalho consiste em um estudo da dispersão e quantificação dos poluentes atmosféricos emitidos por fontes fixas do sistema de recuperação química de uma indústria de papel e celulose Kraft, situada na região sudeste do Estado do Paraná, tomada como estudo de caso. A cidade onde a indústria está localizada não apresenta, como a maioria das cidades brasileiras, 


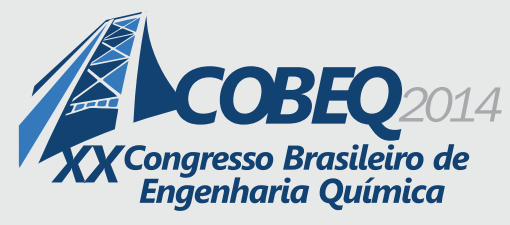

19 a 22 de outubro de 2014
Florianópolis/SC

uma rede de monitoramento para os principais poluentes indicadores da qualidade do ar. Com base no problema apresentado, será realizado um estudo para estimar a concentração e avaliar a dispersão atmosférica dos poluentes material particulado (MP), compostos reduzidos de enxofre (TRS) e óxidos de enxofre $\left(\mathrm{SO}_{\mathrm{x}}\right)$, utilizando o modelo de dispersão atmosférica Aermod como ferramenta de avaliação do impacto ambiental na qualidade do ar sobre a região receptora.

\section{DISPERSÃO DOS POLUENTES E MODELAGEM ATMOSFÉRICA}

A simulação foi executada em uma interface comercial no uso do Software ISC-AERMOD View. O modelo foi aplicado na condição designada para fins regulatórios. Os dados de entrada necessários são: arquivos com dados meteorológicos horários, que neste trabalho foram gerados pelo modelo meteorológico MM5, para o ano 2012; parâmetros físicos e operacionais das fontes emissoras; e a definição de uma malha de receptores a qual representa a área de estudo, onde são estimadas as concentrações. Outros fatores necessários à execução da simulação são o tipo do terreno, que neste caso foi definido como elevado e o coeficiente de dispersão rural, seguindo o método de Auer (AUER, 1978).

As concentrações estimadas pelo modelo de dispersão atmosférica Aermod foram comparadas com os padrões de qualidade do ar da Resolução Conama n003/1990 (BRASIL, 1990) e, particularmente para o caso do poluente TRS, aos valores estabelecidos pela Agência de Proteção Ambiental Americana (USEPA, 1979). No caso do poluente $\mathrm{SO}_{\mathrm{x}}$, a concentração estimada foi considerada para o poluente dióxido de enxofre $\left(\mathrm{SO}_{2}\right)$, pois os padrões de qualidade do ar são estabelecidos somente para o $\mathrm{SO}_{2}$. A simulação para a estimação da concentração de $\mathrm{MP}$ foi executada para Partículas Totais em Suspensão (PTS). Além da verificação do atendimento ao padrão, mapas de concentração foram gerados com o objetivo de verificar o comportamento da dispersão dos poluentes e as áreas impactadas.

\subsection{Fontes emissoras}

Ao todo, foram estudadas oito fontes pontuais específicas do processo Kraft, identificadas e numeradas de 1 a 8 . As características físicas das fontes como: altura da chaminé (h), diâmetro interno no topo da chaminé (D), temperatura de saída dos gases (T) e velocidade de saída dos gases (V) e, taxas de emissão, estão apresentadas no Quadro 1. As principais fontes fixas de emissão do processo que foram simuladas neste estudo compreendem: caldeira de recuperação química, forno de cal, tanque de dissolução, caldeira de biomassa e incinerador.

Quadro 1 - Parâmetros físicos e operacionais das fontes emissoras

\begin{tabular}{|c|c|c|c|c|c|c|c|}
\hline \multirow{2}{*}{ Fontes } & \multicolumn{4}{|c|}{ Parâmetros da fonte } & \multicolumn{3}{c|}{ Taxa de Emissão (g/s) } \\
\cline { 2 - 8 } & $\begin{array}{c}\mathrm{h} \\
(\mathrm{m})\end{array}$ & $\begin{array}{c}\mathrm{D} \\
(\mathrm{m})\end{array}$ & $\begin{array}{c}\mathrm{T} \\
\left({ }^{\circ} \mathrm{C}\right)\end{array}$ & $\begin{array}{c}\mathrm{V} \\
(\mathrm{m} / \mathrm{s})\end{array}$ & MP & TRS & SO $_{\mathrm{x}}$ \\
\hline 1 & 69,5 & 3,2 & 171 & 17 & 3,42 & - & - \\
\hline 2 & 70,0 & 3,0 & 171 & 17 & 3,81 & - & - \\
\hline 3 & 64,1 & 2,9 & 196 & 20 & 8,97 & 0,01 & 0,44 \\
\hline
\end{tabular}




\begin{tabular}{|c|c|c|c|c|c|c|c|}
\hline \multirow{2}{*}{ Fontes } & \multicolumn{4}{|c|}{ Parâmetros da fonte } & \multicolumn{3}{c|}{ Taxa de Emissão (g/s) } \\
\cline { 2 - 8 } & $\begin{array}{c}\mathrm{h} \\
(\mathrm{m})\end{array}$ & $\begin{array}{c}\mathrm{D} \\
(\mathrm{m})\end{array}$ & $\begin{array}{c}\mathrm{T} \\
\left({ }^{\circ} \mathrm{C}\right)\end{array}$ & $\begin{array}{c}\mathrm{V} \\
(\mathrm{m} / \mathrm{s})\end{array}$ & MP & TRS & $\mathrm{SO}_{\mathrm{x}}$ \\
\hline 4 & 65,0 & 3,0 & 196 & 20 & 2,44 & 0,01 & 0,34 \\
\hline 5 & 40,0 & 1,2 & 179 & 23 & 0,78 & 0,01 & - \\
\hline 6 & 40,0 & 1,5 & 179 & 23 & 0,39 & 0,01 & - \\
\hline 7 & 63,8 & 2,6 & 250 & 16 & 0,22 & 0,03 & 0,27 \\
\hline 8 & 59,2 & 1,1 & 89 & 16 & 1,50 & 0,16 & - \\
\hline
\end{tabular}

\subsection{Caracterização da malha de receptores}

A região de estudo compreende uma cidade do centro-leste Paranaense situada nas coordenadas $24^{\circ} 16^{\prime} 37^{\prime \prime}$ Sul e 50³6'58' Oeste a uma altitude de 760 metros. A Figura 1 apresenta uma imagem aérea da cidade, em destaque a localização das fontes emissoras. A simulação abrange um raio de 10 $\mathrm{km}$ sobre a região que inclui a zona urbana.

Foi criada uma malha contendo 2.701 receptores, cobrindo uma área de $900 \mathrm{~km}^{2}$. A distribuição dos mesmos foi feita de maneira diferenciada, conforme também pode ser visto na Figura 1. As fontes emissoras situam-se no cento da malha de receptores da região, com destaque para os pontos vermelhos centrais que as representam.
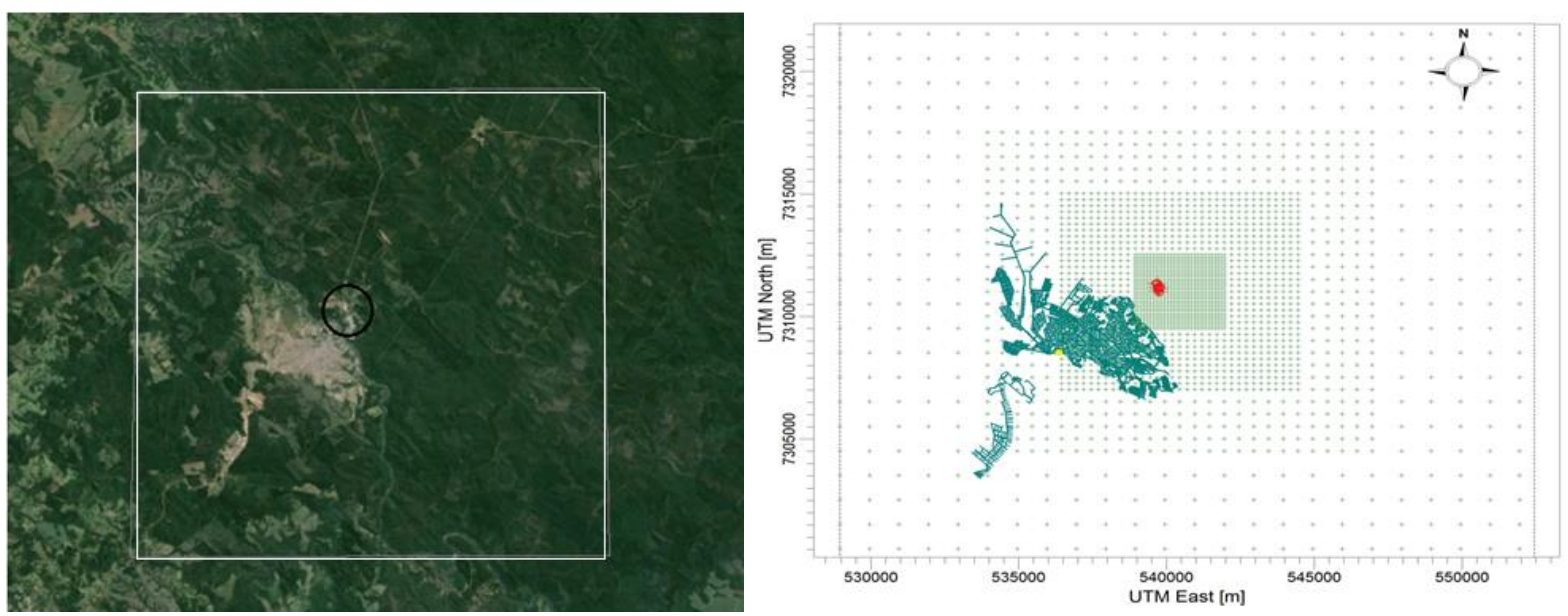

Figura 1 - Delimitação da área de simulação e malha de receptores.

\subsection{Topografia da região}

A caracterização do terreno adjacente às fontes emissoras torna-se importante no estudo da dispersão dos poluentes. Assim, o modelo digital do terreno da área de estudo foi criado com base nos dados do Instituto Nacional de Pesquisas Espaciais (INPE) - Figura 2. Estes dados foram processados no Aermap, e importados no Aermod usando coordenadas UTM, deixando, assim, a simulação georreferenciada. 
A topografia do terreno na extensão estudada varia de 610 a 960 metros. A cidade está situada a uma altitude média de 760 metros. As fontes emissoras estão localizadas a uma altitude média de 730 metros. As regiões que apresentam topografia mais elevada estão a nordeste (NE) e sudoeste (SO) no mapa da área de estudo - Figura 2, com altitude média de 930 a 840 metros respectivamente.

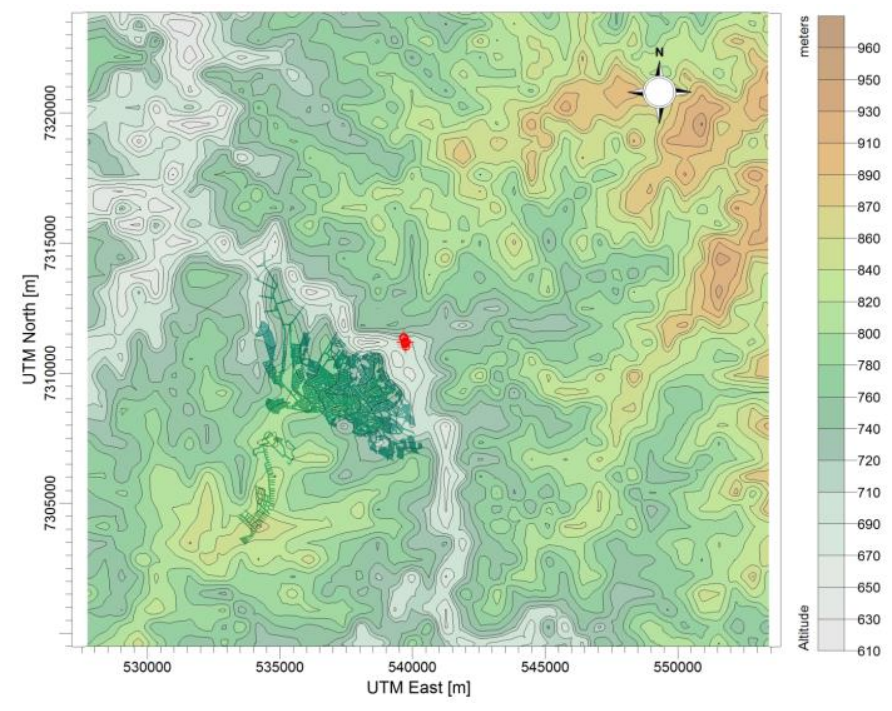

Figura 2 - Modelo digital do terreno.

\subsection{Condições meteorológicas utilizadas na modelagem Aermod}

Os arquivos de dados meteorológicos foram obtidos junto a Lakes Environmental. Os dados foram gerados pelo modelo meteorológico MM5, para o ano de 2012, em dois arquivos, um de superfície e outro de altitude, para o período de 01/01/2012 a 31/12/2012, para todas as horas do dia.

A direção e a velocidade dos ventos para a região de estudo foram representadas pela rosa dos ventos, elaborada com os dados meteorológicos do MM5, como ilustra a Figura 4. Nota-se a predominância dos ventos vindos da direção nordeste (NE), em que o vetor resultante está a $49^{\circ}$, com fluxos de vento soprando para a região sudoeste (SO), em que o vetor resultante está a $229^{\circ}$. A presença de fluxos de ventos para a região sudeste (SE) também podem influenciar o transporte do poluente nesta direção. 


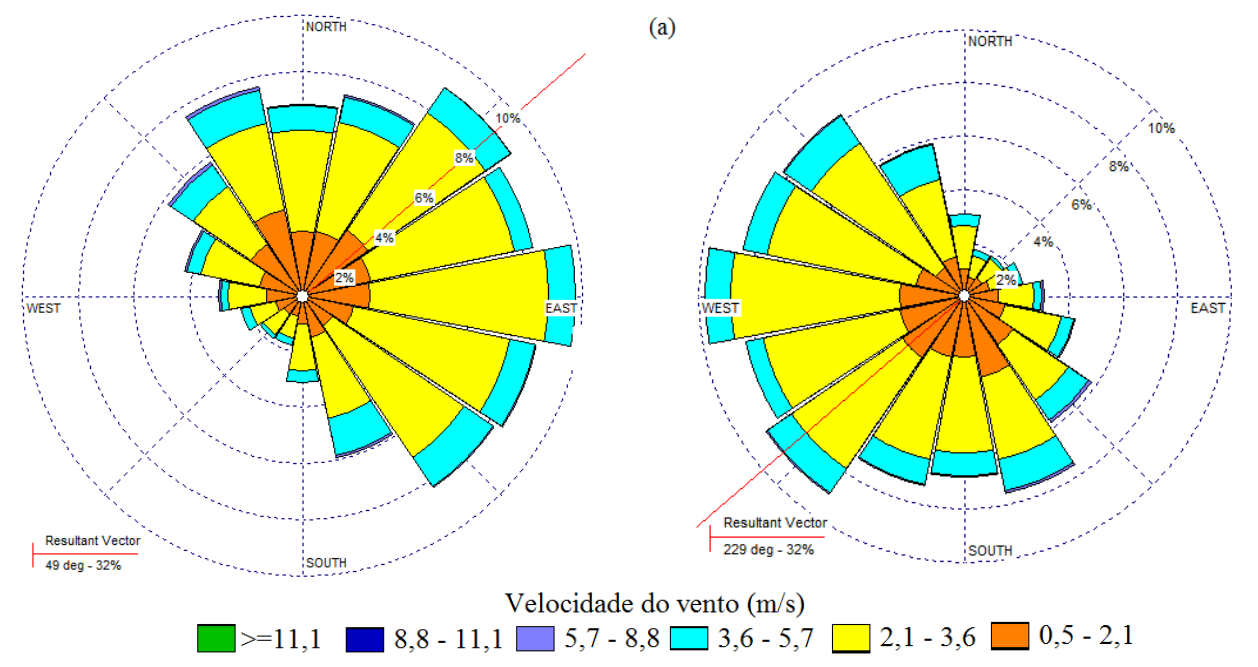

(b)

Figura 4 - Rosa dos ventos gerada para a série de dados para o período do ano de 2012; (a) direção do vento; e (b) fluxo de vento.

\section{RESULTADOS E DISCUSSÕES}

A seguir são apresentados os resultados das simulações da dispersão dos poluentes material particulado (MP), compostos reduzidos de enxofre (TRS) e óxidos de enxofre $\left(\mathrm{SO}_{\mathrm{x}}\right)$. Os mapas de concentração foram gerados para identificar as áreas impactadas e também são apresentados.

\subsection{Concentração média máxima estimada pelo modelo AERMOD}

A estimação da concentração para os poluentes em cada receptor com médias horária, diária e anual são apresentados na Tabela 1.

Tabela 1 - Concentrações máximas simuladas para a emissão dos poluentes MP, TRS e $\mathrm{SO}_{\mathrm{x}}$

\begin{tabular}{|c|c|c|c|c|c|c|c|c|c|}
\hline \multirow{3}{*}{ Média } & \multicolumn{3}{|c|}{$\begin{array}{c}\text { Concentração estimada } \\
\left(\mu / \mathrm{m}^{3}\right)\end{array}$} & \multicolumn{6}{|c|}{$\begin{array}{l}\text { Padrão de Qualidade do ar } \\
\qquad\left(\mu / \mathrm{m}^{3}\right)\end{array}$} \\
\hline & \multirow{2}{*}{$\mathrm{MP}$} & \multirow{2}{*}{ TRS } & \multirow{2}{*}{$\mathrm{SO}_{\mathrm{x}}$} & \multicolumn{2}{|c|}{ PTS* } & \multicolumn{2}{|c|}{ TRS } & \multicolumn{2}{|c|}{$\mathrm{SO}_{2} *$} \\
\hline & & & & $\mathrm{P}$ & $\mathrm{S}$ & $\mathrm{P}$ & $\mathrm{S}$ & $\mathrm{P}$ & $\mathrm{S}$ \\
\hline 1 hora & 55,69 & 2,59 & 3,45 & - & - & 30 & 30 & - & - \\
\hline 24 horas & 12,74 & 0,27 & 0,47 & 240 & 150 & 7 & 7 & 365 & 100 \\
\hline 1 ano & 2,06 & 0,06 & 0,09 & 80 & 60 & - & - & 80 & 40 \\
\hline
\end{tabular}

P - Padrão primário; S - Padrão Secundário. *BRASIL (1990). “USEPA (1979).

Verificou-se que os valores de concentração estimados pelo modelo Aermod com médias diária, horária e anual são inferiores aos valores de concentração estabelecidos pela Resolução Conama $\mathrm{n}^{\circ} 003 / 1990$ para os poluentes $\mathrm{MP}$ e $\mathrm{SO}_{\mathrm{x}}$, e o padrão americano para o poluente TRS. As concentrações com médias horária e diária representam uma fração menor que $10 \%$ dos padrões. A concentração máxima anual representa um valor pouco significante se comparados aos padrões. Não 
houve violação aos padrões de qualidade do ar.

Os mapas de concentração com média diária foram gerados por meio da execução do programa, como mostra a Figura 5, 6 e 7. O círculo branco, em destaque, representa a localização do centro da cidade. No caso do material particulado a pluma do poluente que atingiu o centro da cidade, em destaque, apresentou concentrações máximas diárias entre 0,37 a $4,49 \mu \mathrm{g} / \mathrm{m}^{3}$. A região a sudoeste da cidade também foi impactada pela pluma do poluente, com máxima concentração diária entre 1,74 e $4,49 \mu \mathrm{g} / \mathrm{m}^{3}$, devido à predominância de fluxos de vento nesta direção e a cotas topográficas elevadas, em média a região sudoeste apresenta uma latitude de $840 \mathrm{~m}$. As maiores concentrações diárias estão entorno as fontes emissoras, localizadas a noroeste e sudeste com valores de $11,37 \mu \mathrm{g} / \mathrm{m}^{3}$.

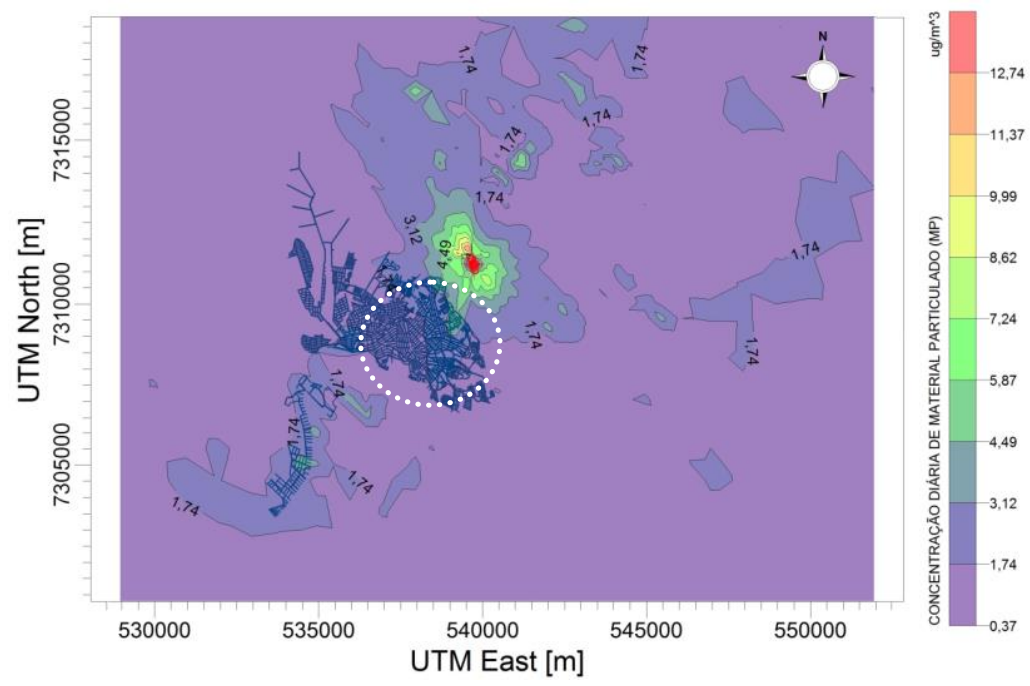

Figura 5 - Mapa de concentração com média diária (24h) para MP.

Ao avaliar as áreas atingidas pelos poluentes da classe TRS, o mapa de concentração com média diária foi gerado por meio da execução do programa, como ilustra a Figura 6. A dispersão do poluente se dividiu em três regiões isoladas em áreas concentradas. A concentração diária atingiu valores entre $0,06 \mu \mathrm{g} / \mathrm{m}^{3}$ e $0,09 \mu \mathrm{g} / \mathrm{m}^{3}$, no centro da cidade e na região sudoeste do município. Já a região a noroeste das fontes emissoras, apresentou maiores concentrações, com valores de $0,24 \mu \mathrm{g} / \mathrm{m}^{3}$ próximos às fontes e concentrações entre 0,15 e $0,18 \mu \mathrm{g} / \mathrm{m}^{3}$, na mesma direção, porém mais distantes das fontes, em cotas topográficas elevadas a uma altitude média de $800 \mathrm{~m}$. Verifica-se a influência da direção do vento e topografia na dispersão dos poluentes, além da influência da proximidade as fontes emissoras. 


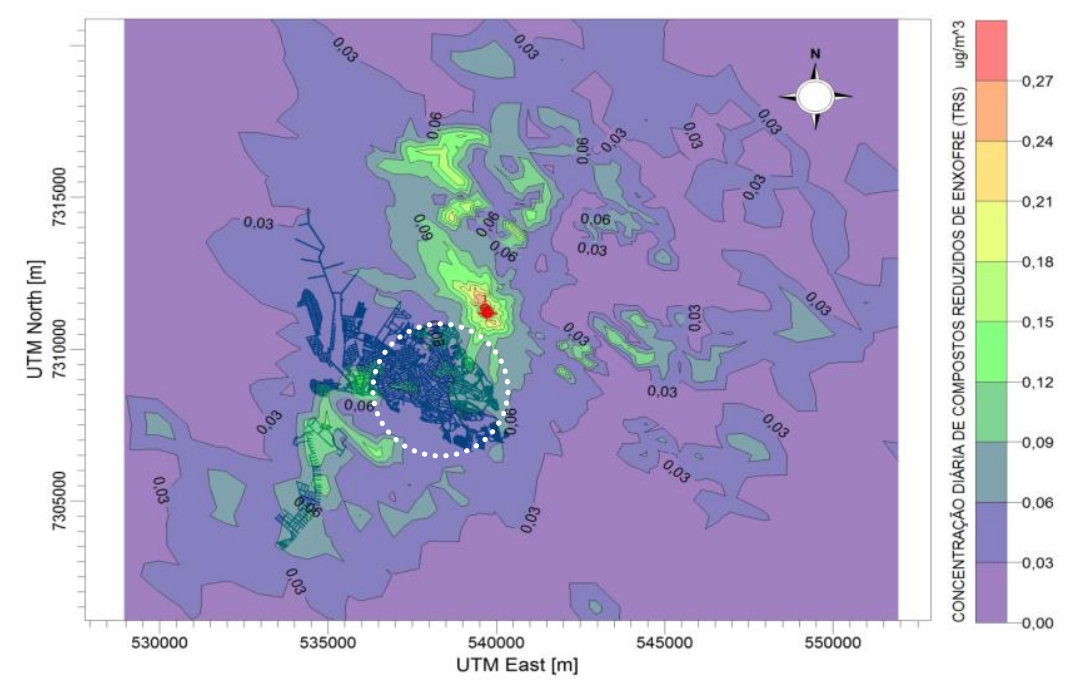

Figura 6 - Mapa de concentração com média diária (24h) para TRS.

A Figura 7 ilustra a distribuição das concentrações do poluente $\mathrm{SO}_{\mathrm{x}}$ como $\mathrm{SO}_{2}$. As áreas mais impactadas, com médias diárias, estão localizadas, principalmente, a noroeste das fontes, chegando a valores de até $0,42 \mu \mathrm{g} / \mathrm{m}^{3}$. O centro da cidade não foi o mais impactado, sendo a máxima concentração de $0,10 \mu \mathrm{g} / \mathrm{m}^{3}$. O transporte do poluente se deu de forma difusa, com concentrações máxima de $0,16 \mu \mathrm{g} / \mathrm{m}^{3}$ a $0,21 \mu \mathrm{g} / \mathrm{m}^{3}$, encontradas em todas as direções entorno à região de estudo, porém em núcleos isolados com cotas topográficas elevadas de ordem acima de $840 \mathrm{~m}$.

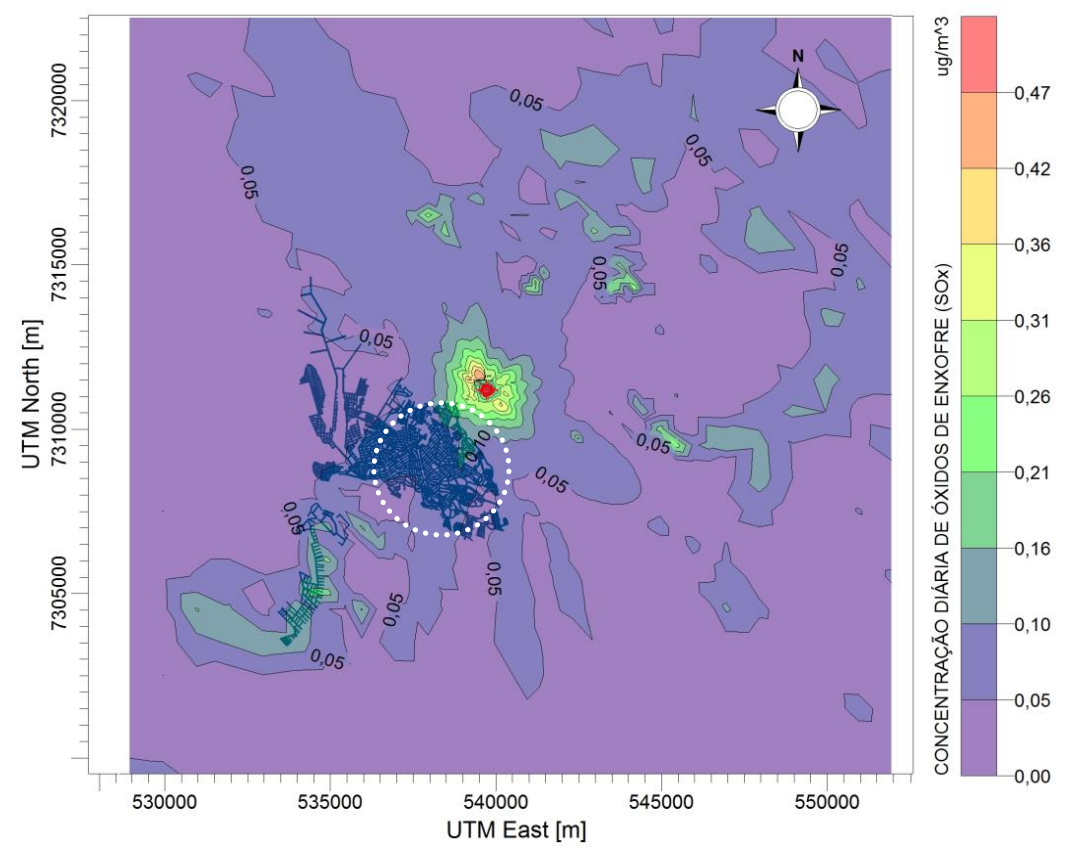

Figura 7 - Mapa de concentração com média diária (24h) para o $\mathrm{SO}_{\mathrm{x}}$ como SO2. 


\section{CONCLUSSÕES}

Com base nos resultados obtidos nas simulações, verificou-se que não houve violação aos padrões de qualidade do ar estabelecidos pela Resolução Conama n ${ }^{\circ} 003 / 1990$ e padrões da USEPA para o poluente TRS. Nos demais casos simulados, considerando a concentração média existente na região, nem as máximas concentrações ultrapassam os padrões de qualidade do ar. As áreas mais impactadas estão a noroeste e sudeste das fontes, para a maioria dos casos. As maiores concentrações com médias diária e horária ocorrem devido à proximidades das fontes e em cotas topográficas elevadas em relação à fontes de emissão, situações fundamentais que resultam em áreas com maiores concentrações para estas médias. $\mathrm{O}$ modelo pode ser utilizado de maneira qualitativa indicando os possíveis pontos de medidas da concentração de poluentes em uma rede de monitoramento da qualidade do ar. Mostrou-se, ainda, como uma ferramenta estratégica para a gestão e o controle da poluição do ar tanto para a indústria, como para a região receptora e impactada pelas emissões industriais.

\section{REFERENCIAS}

AUER, A. H. JR. Correlation of land use and cover with meteorological anomalies. J. Appl. Meteor., p. 636-643, 1978.

BRASIL. Resolução $n^{\circ}$ 003, de 28 de junho de 1990. Brasília, DF.

BRASIL. Resolução $n^{\circ}$ 054, de 22 de dezembro de 2006. Brasília, DF. 2006a.

COMPANHIA AMBIENTAL DO ESTADO DE SÃO PAULO (CETESB). Relatório de Qualidade do ar no Estado de São Paulo: relatório técnico. São Paulo: CETESB, 2012. Disponível em: <http://www.cetesb.sp.gov.br/ar/qualidade-do-ar/31-publicacoes-e-relatorios>. Acesso em: 15 ago. 2013.

INSTITUTO AMBIENTAL DO PARANÁ (IAP). Fontes de poluição atmosférica. 2013. Disponível em: 〈http://www.iap.pr.gov.br/modules/conteudo/conteudo.php?conteudo=130>. Acesso em: 10 ago. 2012.

UNITED STATES ENVIRONMENTAL PROTECTION AGENCY (USEPA). Control of TRS emission from existing mills. Kraft Pulping, March, 1979. 